\title{
ИНТЕРПРЕТАЦИЯ ГЕОЛОГО-ГЕОФИЗИЧЕСКИХ ДАННЫХ ДЛЯ ИДЕНТИФИКАЦИИ НЕОДНОРОДНОСТЕЙ СКАЛЬНОГО МАССИВА ПО ДАННЫМ ЭЛЕКТРОМАГНИТНОГО ЗОНДИРОВАНИЯ
}

\section{Дьяков А.Ю., Калашник А.И.}

Горный институт КНЦРАН, Anamumbl,dyakov@goi.kolasc.net.ru; kalashnik@goi.kolasc.net.ru

Интерпретация геолого-геофизических данных основана на взаимосвязи геофизических аномалий с геологическими факторами, что позволяет выявлять неоднородности (зоны трещиноватости, тектонических нарушений и т.п.) в массиве скальных пород, форма и размеры которых меняются в широких пределах. Вследствие многообразия геолого- геофизических условий, стандартной методики интерпретации геофизических данных, подходящей для большинства случаев, не существует. В том числе, не смотря на все более активное применение электромагнитного зондирования в горном деле различными исследователями, вопросы оценки геолого-структурного строения массивов скальных пород с их помощью остаются не решенными $[2,3,5]$. Существенным недостатком электромагнитного зондирования, как и у большинства волновых методов, является сложность камеральной обработки полученных данных, а также неоднозначность интерпретации, на качество которой влияет опыт интерпретатора. Целью данной работы являлась разработка комплексного подхода (сопоставления данных имитационного моделирования, визуального обследования и анализа кинематических и динамических характеристик сигнала электромагнитного зондирования) к интерпретации геолого-геофизических данных для идентификации наклонных неоднородностей и снижения роли субъективных факторов в процессе интерпретации, что позволит существенно повысить их достоверность.

В подповерхностной георадиолокации распространение электромагнитных волн метрового и дециметрового диапазона в геологической среде-диэлектрике описывается уравнениями Максвелла:

$$
\nabla^{2} \vec{E}-\frac{\varepsilon \partial \vec{E}}{c^{2} \partial t^{2}}-\mu_{0} \sigma \frac{\partial \vec{E}}{\partial t}=0
$$

где $\vec{E}$ - напряженность электрического поля (В/м); $\varepsilon$ - действительная часть комплексной относительной диэлектрической проницаемости (безразмерная величина); с - скорость распространения электромагнитной волны в пространстве (м/с); $\mu_{0}$ - магнитная проницаемость среды (Г/м); $\sigma$ - проводимость (См/м).Идея метода заключается в излучении импульсов электромагнитных волн и регистрации сигналов, отраженных от границ неоднородностей зондируемого массива пород, имеющих отличающиеся электрофизические свойства [6].

Для выявления влияния на состояние массива пород нарушений крупного порядка и понимания механизма формирования особенностей волновых характеристик сигнала, выполнено моделирование электромагнитного поля, индуцированного георадарным зондированием на участке скальных пород с наклонной неоднородностью. Расчеты выполнены методом конечных разностей во временной области с использованием программ GPRMAX и MATGPR $[1,8,9]$.

На рис. 1 представлены результаты имитационного моделирования работы георадара с частотой опробования 100 МГц над зоной неоднородности, находящейся под углом $45^{\circ}$ к поверхности. В левой части рисунка (рис. 1 а) показана типичная наклонная структурная неоднородность на уступе карьера. Геометрическая схема модели отображает разрез фрагмента уступа размером $20 * 15$ метров (рис. 1 б), с зоной неоднородности длинной 2 м и мощностью 0.1 м. Диэлектрическая проницаемость вмещающих монолитных пород принята 6 ед. (согласно справочных данных физических свойств горных пород значения диэлектрической проницаемости могут быть 4-8 ед.) [7], а нарушенной структуры, в целях контрастности получаемых данных, в два раза больше - 12 ед. Анализ необработанной синтетической радарограммы (рис. 1 в) позволил выявить амплитудные изменения волновой формы сигнала, отраженной от неоднородности. Выявлено, что при пересечении краев неоднородности образовываются два гиперболических отражения, которые маскируют полезный сигнал. 
Для восстановления истинного положения объекта применена процедура миграции, в которой идея процедуры обработки основана на принципе Гюйгенса, где каждая точка волнового фронта является вторичным источником колебаний. На рисунке 1 е представлена волновая форма сигнала (трасса), проходящая непосредственно посередине неоднородности (рис. 1 д), которая содержит истинное отражение от объекта - красная пунктирная стрелка. На рис. 1 г «хвосты» гипербол (указаны зелеными пунктирными стрелками) маскируют полезный сигнал - истинным отражением от объекта являются вершины гипербол, обозначенные красными пунктирными стрелками. Таким образом, посредством математического моделирования установлена волновая картина осей синфазности и амплитудных характеристик сигнала электромагнитного зондирования уступа, ослабленного наклонной неоднородностью.

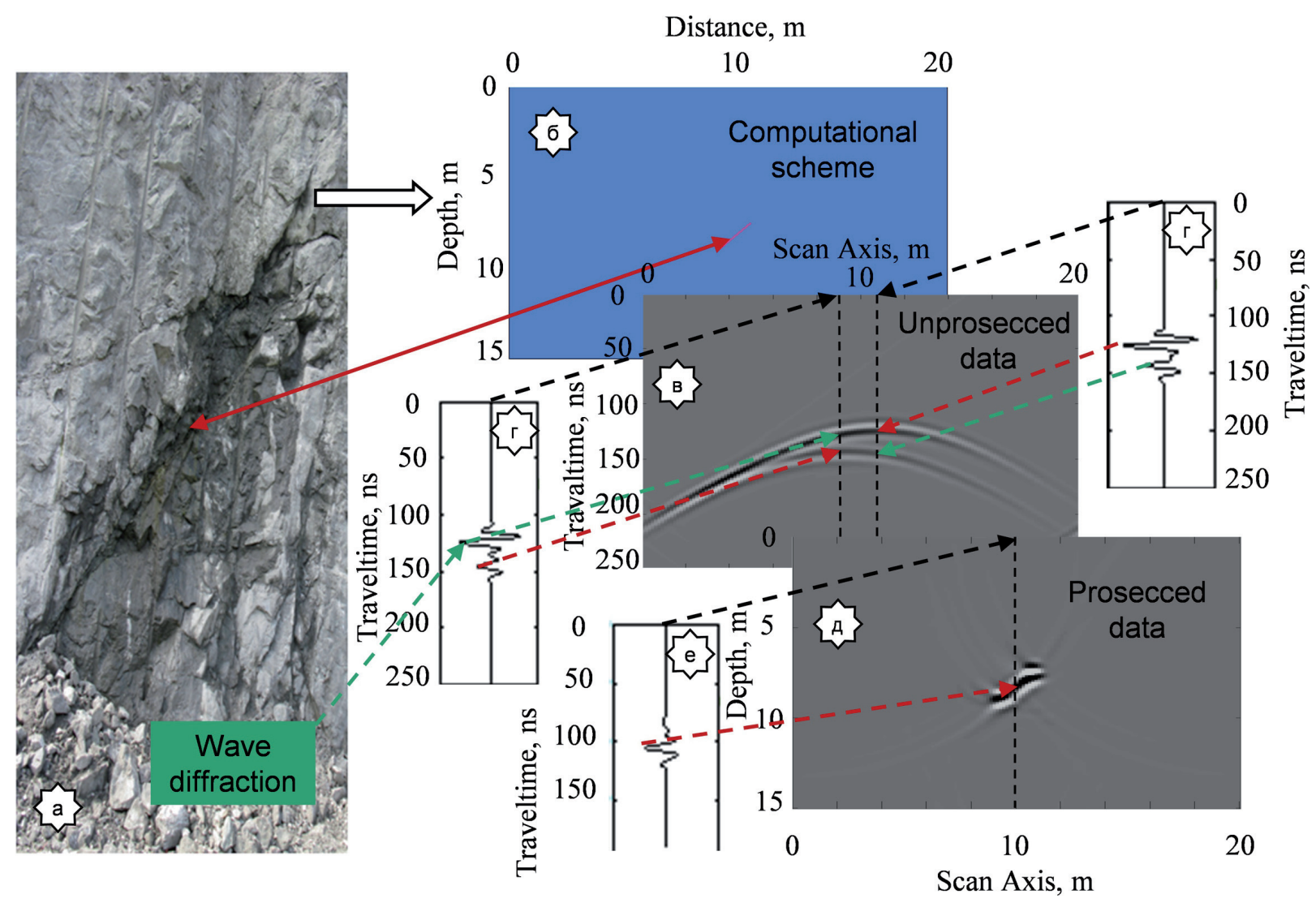

Рис. 1. Алгоритм и результаты моделирования электромагнитного поля, индуцируемого электромагнитным зондированием, в окрестности наклонной неоднородности.

a - неоднородность на уступе карьера, б - геометрическая схема модели, в - синтетическая модель радарограммы, г, е - волновая форма сигнала в точке, д - обработанная радарограмма.

Количественная интерпретация геофизических данных является самым важным этапом получения достоверной информации о структуре массива скальных пород. Интерпретация заключается в детальном анализе волновой картины внутри выделенных на радарограмме участков или областей, которые отличаются друг от друга характером рисунка, либо поверхностями угловых несогласий $[4,6]$.

На рисунке 2 представлен участок обследования крупных трещин (северо-западный борт, горизонт +120 м. карьера Железный АО «Ковдорский ГОК»), проходящих через несколько уступов, в значениях диэлектрической проницаемости, отражающей состояние массива с сопоставлением визуального обследования. Результаты георадарного исследования геолого-структурного строения массива скальных пород вначале обрабатывались с использованием специализированных для данного вида исследований компьютерных программ (ГЕОРАДАР-ЭКСПЕРТ и RadExplorer), 
интерпретировались раздельно, а затем выполнялся комплексный анализ полученных данных в пространственно-глубинной взаимосвязи.

Для вычисления значений диэлектрической проницаемости использовалась программа автоматизированной обработки сигналов ГЕОРАДАР-ЭКСПЕРТ, где исходными данными служила числовая матрица амплитуд отраженных сигналов, полученная при электромагнитном зондировании. В результате вычислений на выходе формируется матрица того же размера, но уже со значениями диэлектрической проницаемости для каждой точки двумерного пространства разреза (технология основана на эффекте дифракции), что позволяет производить построение разрезов как в случае наличия отражающих границ, так и в случае непрерывного изменения электрофизических свойств по профилю наблюдений и по глубине [4]. Значения относительной диэлектрической проницаемости 6.5 отн. ед. были приняты соответствующими однородному состоянию скального массива $[4,7]$. Увеличение диэлектрических свойств пород до 8 отн. ед. в приповерхностной зоне объясняется ее повышенной нарушенностью, что подтверждается визуальным обследованием вертикального обнажения пород. Следовательно, возрастание значений диэлектрической проницаемости от 6.5 до 8 и выше отн. ед. свидетельствует о большей степени неоднородности массива скальных пород.

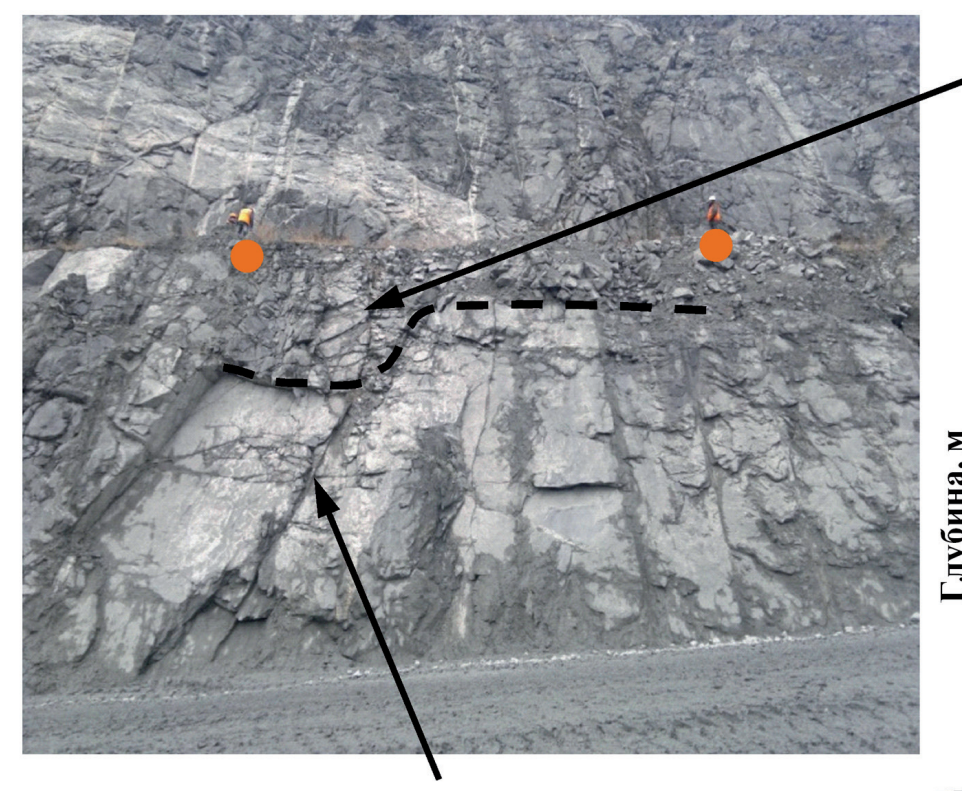

Выявленная трещина

Цветовая шкала значений (верхняя - v [cм/нс], нижняя - $\operatorname{Re}(\varepsilon)$ ):

\section{Нарушенная зона}

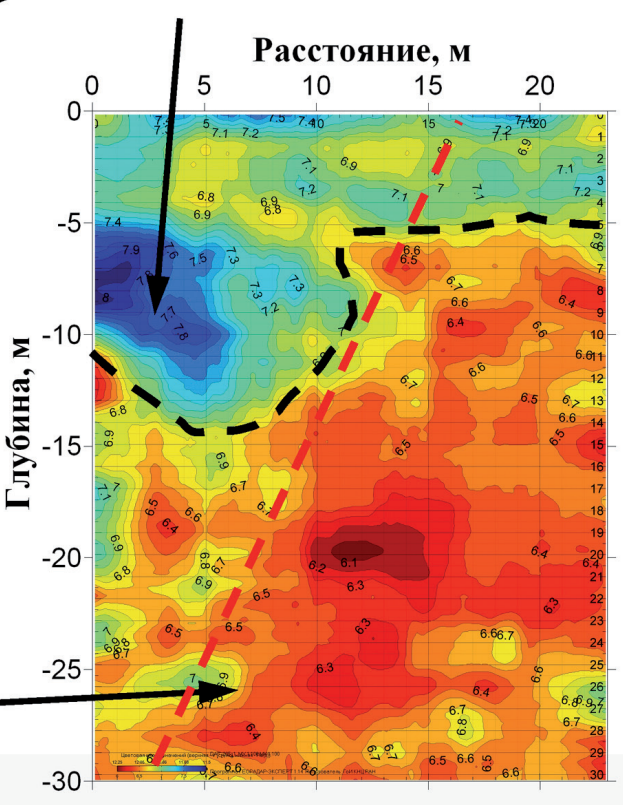

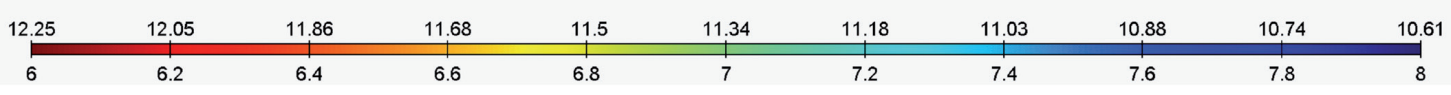

Рис. 2. Радарограмма и ее сопоставление с обнажением пород на уступе (начало и конец профиля обозначены на фото оранжевыми метками).

На рисунке 3 представлено сопоставление значений диэлектрической проницаемости и локальных максимумов амплитуд огибающей электромагнитного сигнала (полученных в программе RadExplorer) по глубине. Выявлено, что увеличение диэлектрической проницаемости соответствует высоким значениям локальных максимумов амплитуд огибающей электромагнитного сигнала, и наоборот.

Выполненными инструментальными измерениями выявлено, что в пределах зон неоднородностей массива (разломная тектоника, участки повышенной трещиноватости) наведенное электромагнитное поле искажается в зависимости от степени различия физических свойств пород зоны и основного массива. Установлено, что интенсивность искажения волнового поля определяется контрастностью (соотношением) физических свойств пород и глубиной расположения зоны. 

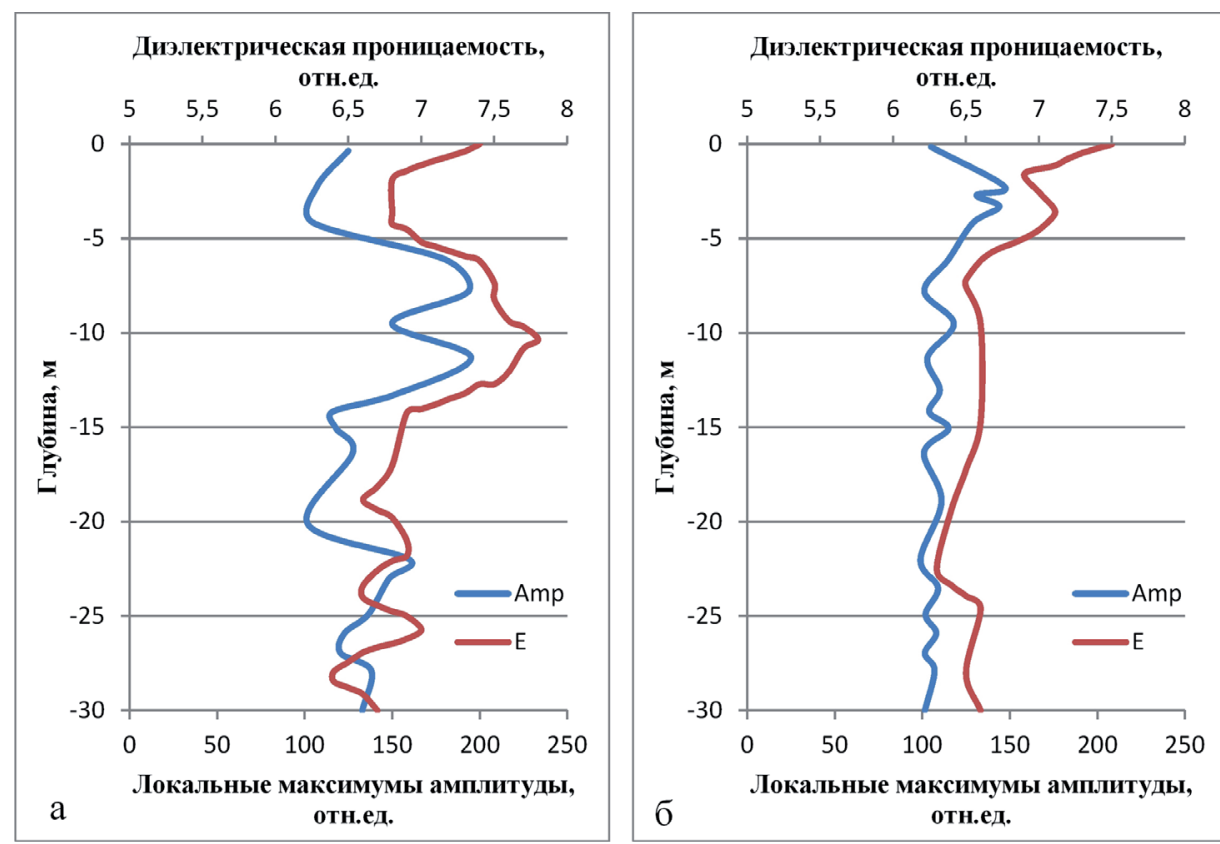

Рис. 3. Сопоставление значений диэлектрической проницаемости пород (Е) и локальных максимумов амплитуд (Amp) огибающей электромагнитного сигнала по данным натурных измерений: a - пятый метр профиля, б - двадцатый метр профиля.

В результате имитационного моделирования установлен механизм формирования особенностей волновой картины осей синфазности и амплитудных характеристик сигнала радарограммы скальных пород, ослабленных наклонной неоднородностью. Сопоставительный анализ данных, с одной стороны, полученных натурными определениями с применением георадарного зондирования, а с другой - по результатам моделирования электромагнитного поля, индуцированного георадарным зондированием, позволил создать основу для более надежного установления параметров наклонной структурной неоднородности по интервалам изменения значений диэлектрической проницаемости пород. Тем самым обоснованы принципы идентификации структурных нарушений и зон неоднородностей в скальном массиве по волновым данным экспериментальных радарограмм натурных георадарных определений.

\section{Литература}

1. Дьяков А.Ю., Калашник А.И. Моделирование электромагнитного поля, индуцированного георадарным зондированием в окрестности структурной неоднородности скального массива // Тр. Ферсмановской научной сессии ГИ КНЦ РАН. 2017. № 14. С. 275-278.

2. Калашник А.И., Казачков С.В., Сохарев В.А., Запорожец Д.В., Дьяков А.Ю. Выявление дислокаций в скальных горнотехнических конструкциях // Вестник Мурман. гос. тех. университета. 2013.Т.16. № 1. C. 93-97.

3. Калашник А.И., Запорожец Д.В., Дьяков А.Ю., Казачков С.В., Сохарев В.А. Исследования георадарами структуры и текущего состояния горных пород, слагающих уступы основного карьера Ковдорского ГОКа // Горный журнал. 2014. № 4. С.60-64.

4. Калашник А.И., Дьяков А.Ю. Оценка нарушенности скальных пород уступа карьера электромагнитным зондированием // Горн.информ. - аналит. бюл. 2015. Глубокие карьеры. Спец. вып. № 56. С. 230-238.

5. Мельников Н.Н., Калашник А.И., Запорожец Д.В., Дьяков А.Ю., Максимов Д.А. Опыт применения георадарных подповерхностных исследований в западной части Российского сектора Арктики // Проблемы Арктики и Антарктики. 2016. № 1 (107). С. 39-49.

6. Старовойтов А.В. Интерпретация георадиолокационных данных. М.: Изд. МГУ, 2008. 192 с.

7. Турчанинов И.А. и др. Атлас физических свойств минералов и пород Хибинских месторождений. Л.: Наука. 1975. $71 \mathrm{c.}$

8. Tzanis A. and Kafetsis G. A freeware package for the analysis and interpretation of common-offset Ground Probing Radar data, based on general purpose computing engines. // Bulletin Geol. Soc. Greece. 2004.V. 36. No 3. P. 1347-1354.

9. Tzanis A. MatGPR Release 2: A freeware MATLAB ${ }^{\circledR}$ package for the analysis \& in-terpretation of common and single offset GPR data // FastTimes. 2010. 15 (1).P. 17-43. 